\title{
Using post-deformation annealing to optimize the properties of a ZK60 magnesium alloy processed by high-pressure torsion**
}

\author{
By Seyed A. Torbati-Sarraf, "Shima Sabbaghianrad and Terence G. Langdon
}

\author{
[*] Dr. S.A. Torbati-Sarraf \\ Departments of Aerospace \& Mechanical Engineering and Materials Science, \\ University of Southern California, Los Angeles, CA 90089-1453, U.S.A. \\ E-mail: torbatis@usc.edu \\ Dr. S. Sabbaghianrad \\ Departments of Aerospace \& Mechanical Engineering and Materials Science, \\ University of Southern California, Los Angeles, CA 90089-1453, U.S.A. \\ Prof. T.G. Langdon \\ Departments of Aerospace \& Mechanical Engineering and Materials Science, \\ University of Southern California, Los Angeles, CA 90089-1453, U.S.A. \\ Materials Research Group, Faculty of Engineering and the Environment, University of Southampton, \\ Southampton SO17 1BJ, UK \\ [**] The authors acknowledge the support provided by the National Science Foundation of the \\ United States under Grant No.DMR-1160966.
}

A ZK60 magnesium alloy with an initial grain size of $\sim 10 \mu \mathrm{m}$ was processed by highpressure torsion (HPT) through 5 revolutions under a constant compressive pressure of $2.0 \mathrm{GPa}$ with a rotation speed of $1 \mathrm{rpm}$. An average grain size of $\sim 700 \mathrm{~nm}$ was achieved after HPT with a high fraction of high-angle grain boundaries. Tensile experiments at room temperature showed poor ductility. However, a combination of reasonable ductility and good strength was achieved with post-HPT annealing by subjecting samples to high temperatures in the range of 473 to $548 \mathrm{~K}$ for 10 or $20 \mathrm{~min}$. The grain size and texture changes were also examined by electron back scattered diffraction (EBSD) and the results compared to long-term annealing for $2500 \mathrm{~min}$ at $450 \mathrm{~K}$. The results of this study suggest that a post-HPT annealing for a short period of time may be effective in achieving a reasonable combination of strength and ductility.

Keywords: ductility; high-pressure torsion; post-deformation annealing; ultrafine grain size; ZK60 magnesium alloy 


\section{Introduction}

Magnesium and its alloys are considered the lightest structural alloys available on earth. Having exceptional mechanical properties makes these alloys promising for use in a very wide range of applications including in aerospace, ${ }^{[1]}$ automotive,${ }^{[2]}$ biomedical $^{[3]}$ and electronic devices. ${ }^{[4]}$ Nevertheless, magnesium alloys suffer from poor formability at room temperature because of the limited numbers of slip systems available in h.c.p. metals and accordingly attempts have been made to improve their ductility by introducing an ultrafine grained (UFG) structure through the application of severe plastic deformation (SPD) ${ }^{[5]}$ An important SPD procedure for producing a UFG structure is high-pressure torsion $(\mathrm{HPT})^{[6]}$ where a sample, generally in the form of a thin disk, is subjected to a high applied pressure and concurrent torsional straining. Typically, processing by HPT produces average grain sizes of the order of $\sim 1 \mu \mathrm{m}$ or smaller and this provides a capability for achieving both high strength at room temperature ${ }^{[7,8]}$ and high superplastic ductilities at elevated temperature. ${ }^{[9]}$ However, UFG metals generally exhibit poor ductility at room temperature due to their low rate of strain hardening and low strain rate sensitivity. ${ }^{[10,11]}$

Several techniques have been proposed in order to enhance the ductility after SPD processing. For example, subjecting the processed material to a short-term annealing was investigated with an $\mathrm{Al}-1 \% \mathrm{Mg}$ alloy ${ }^{[12]}$ and with pure $\mathrm{Ta}^{[13]}$. With the Al-Mg alloy it was observed that a post-HPT annealing treatment for only 10 min decreased the strength by $<25 \%$ but at the same time produced reasonable elongations to failure with engineering strains of $>0.2 .{ }^{[12]}$ Postdeformation annealing for $15 \mathrm{~min}$ also gave significant ductility in the samples of pure Ta. ${ }^{[13]}$ Studies on $\mathrm{Cu}$ processed by ECAP revealed that short term annealing has the potential of ordering the defect structure within the grain boundaries and thereby producing more equilibrated grain 
boundaries without introducing significant grain growth. ${ }^{[14]}$ Other studies demonstrated a ductility enhancement after the SPD processing of Ti alloys followed by short term annealing. ${ }^{[15-18]}$

It is generally accepted that plastic deformation processes through conventional forming methods, such as rolling, drawing or extrusion, can enhance the strength of metals through the Hall-Petch relationship ${ }^{[19,20]}$ but these results are accompanied by a loss of ductility which leads to the so-called paradox of strength and ductility where metals are not simultaneously both strong and ductile. ${ }^{[21]}$ It was reported recently that an exceptional combination of high strength and high ductility (HSHD) may be produced in an aluminum-based alloy by imposing a sufficiently high strain through SPD processing ${ }^{[22,23]}$ but this approach has not been explored in any detail and no similar results are currently available for any h.c.p. metals.

Based on the data available to date it appears that, in order to increase the ductility at low temperatures after SPD processing, the simplest approach is probably to make use of postdeformation annealing and some limited data are already available demonstrating the feasibility of this approach for nanostructured Titanium. ${ }^{[24]}$ Earlier studies on the magnesium ZK60 alloy confirmed the development of excellent high temperature ductility through the formation of a UFG structure after processing by $\mathrm{HPT}^{[8,25-30]}$ and therefore the present research was initiated to provide a first comprehensive analysis of the effect of post-deformation annealing on the strength properties of the ZK60 alloy.

\section{Experimental material and procedures}

The experiments were conducted using commercially available extruded rods of the ZK60 magnesium alloy with a nominal chemical composition of Mg-5.5 wt.\% Zn-0.5 wt.\% Zr. The extruded rods had diameters of $10 \mathrm{~mm}$ and they were sliced perpendicular to the extrusion direction 
to give disks with thicknesses of $\sim 1.2 \mathrm{~mm}$. Both sides of these sliced disks were carefully ground with a series of abrasive papers to give ultimate thicknesses of $\sim 0.82 \mathrm{~mm}$.

The processing by HPT was conducted under quasi-constrained conditions ${ }^{[31,32]}$ in which there is a small outflow of material around the periphery of the disk during the processing operation. The HPT was conducted at room temperature (RT) under an applied pressure, $P$, of 2.0 GPa with a constant rotation speed of $1 \mathrm{rpm}$. All disks were processed through a total number, $N$, of 5 revolutions. Visual inspection revealed no damage or cracking during the processing operation and there was no evidence for any slippage of the disks. ${ }^{[33]}$

Following 5 turns of HPT, disks were subjected to isothermal annealing under selected conditions. Some disks were annealed at $450 \mathrm{~K}$ for $2500 \mathrm{~min}$ in order to evaluate the long-term thermal stability of the microstructure but other disks were annealed for short periods of 10 or 20 min at selected temperatures within the range from 473 to $548 \mathrm{~K}$. All annealing was performed in an air-circulated furnace with the temperature maintained constant to within an accuracy of $\pm 1 \mathrm{~K}$.

Microstructural observations were made on the top surfaces of the disks. Electron backscatter diffraction (EBSD) was used to investigate the microstructure at the mid-radius positions of the cross-sections of the disks. Samples were prepared for EBSD using a JEOL IB09010CP ion beam cross-sectional polishing facility with the polishing conducted at an operating voltage of 6 $\mathrm{kV}$ for $5 \mathrm{~h}$. An analytical field emission scanning electron microscope (SEM) JEOL JSM-7001F was used at an operating voltage of $7 \mathrm{kV}$ with orientation imaging microscopy (OIM) utilized to record the data. In this study the directions ND, TD and RD correspond to the Normal (torsion axis), Tangential and Radial Directions, respectively, and the shear direction lies parallel to TD. Low-angle grain boundaries (LAGBs) were defined by the software as boundaries having misorientation differences between adjacent measuring points of $2^{\circ}-15^{\circ}$ and high-angle grain 
boundaries (HAGBs) were defined as having misorientation differences of more than $15^{\circ}$. The pole figures in the EBSD images were measured from the corresponding EBSD maps of samples in the TD-RD plane.

Microhardness measurements were carried out on the top surfaces of the HPT-processed disks. All samples were polished to achieve mirror-like surfaces by removing a layer of up to $\sim 0.1$ $\mathrm{mm}$ from each surface before taking any measurements. The Vickers microhardness values, $\mathrm{Hv}$, were recorded at RT using an FM-1e microhardness instrument equipped with a Vickers indenter under a load of $100 \mathrm{gf}$ with a dwell time of $10 \mathrm{~s}$ for each separate measurement. The indentation tests were conducted along a randomly selected diagonal line across each disk. Incremental distances of $0.3 \mathrm{~mm}$ were chosen between each separate indentation point. The hardness values were recorded as the average of four indentations formed in a cross-shape around the selected point at distances from the point of $0.15 \mathrm{~mm}$.

The mechanical properties were evaluated after HPT processing by using tensile testing of miniature samples. Two miniature tensile samples were cut from each disk after HPT processing with the disks arranged in off-center positions to avoid any potential problems associated with microstructural inhomogeneities near the disk centers. ${ }^{[34]}$ Electrical discharge machining (EDM) was employed to cut the miniature tensile specimens from the disks in order to obtain dimensionally-precise samples and to avoid the introduction of any mechanical damage. The gauge lengths of the tensile samples were $1.0 \mathrm{~mm}$ and the cross-sectional areas were approximately $1.0 \times 0.64 \mathrm{~mm}^{2}$. All of the tensile testing was conducted at RT using an Instron testing machine operating at a constant rate of crosshead displacement with initial strain rates in the range from 1.0 $\times 10^{-4}$ to $3.0 \times 10^{-3} \mathrm{~s}^{-1}$. All specimens were pulled to failure and the recorded load-displacement 
curves were then converted to engineering stress versus engineering strain. For each sample, the flow stresses and the elongations to failure were determined directly from the stress-strain curves.

\section{Experimental results}

\subsection{Effect of post-deformation annealing on microstructural evolution}

The objective of this research was to evaluate the effect of post-deformation annealing on the ZK60 alloy after processing through 5 turns of HPT. Samples were annealed isothermally for 10 or $20 \mathrm{~min}$ at constant temperatures of 473,523 or $548 \mathrm{~K}$ and, in addition, the long-term stability was investigated by annealing samples at $450 \mathrm{~K}$ for $2500 \mathrm{~min}$. Figure 1 provides a montage of image quality (IQ) micrographs of the material (a) after processing by HPT and after HPT and post-deformation annealing (b) for $2500 \mathrm{~min}$ at $450 \mathrm{~K}$, (c) for $20 \mathrm{~min}$ at $473 \mathrm{~K}$ and (d) for $20 \mathrm{~min}$ at $548 \mathrm{~K}$. Using these and similar micrographs, Figure 2 provides plots of the distributions in grain sizes for these different testing conditions.

It is apparent from Figure 1(a) and 2(a) that the processing by 5 turns of HPT produces a majority of fine grains although some limited numbers of coarser grains also remain within the microstructure. This result matches earlier reports describing the application of HPT to this alloy ${ }^{[25-27,30]}$ and also to the AZ31 magnesium alloy. ${ }^{[35,36]}$ There is some evidence in Figure 2(a) for a bi-modality in the grain size distribution with a peak around $\sim 0.3 \mu \mathrm{m}$ and another broader peak at $\sim 1.0 \mu \mathrm{m}$. The formation of a bi-modality in the grain distribution is frequently reported in magnesium alloys and it is due primarily to the formation of a necklace structure during the early stages of grain refinement. ${ }^{[37,38]}$ Nevertheless, it is clear that long-term annealing produces a uniform grain structure with no evidence for a bi-modality as shown in Figure 2(b). Annealing for $2500 \mathrm{~min}$ at $450 \mathrm{~K}$ produces a reasonably equiaxed grain structure with an average grain size of $\sim 2.1 \mu \mathrm{m}$ and with few grains having sizes of $<1 \mu \mathrm{m}$ or $>10 \mu \mathrm{m}$. 
By contrast, short-term annealing for 20 min leads to the occurrence of some larger grains with sizes $>10 \mu \mathrm{m}$ and this provides clear evidence for the occurrence of abnormal grain growth during the annealing process. Figures $2(\mathrm{c})$ and (d) both show the presence of a small number of exceptionally large grains that were not present in the initial material.

The relevant EBSD maps for these four processing conditions are shown in Figure 3 with the grain orientations depicted by different colors which correspond to the colors shown in the unit triangle below the images. In these maps, the LAGBs and HAGBs are delineated by yellow and

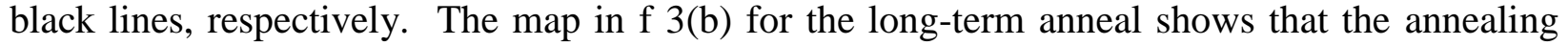
produces more random grain orientations by comparison with the short-term anneals shown in Figures 3(c) and (d). It is apparent that the new recrystallized grain orientations are primarily dominated by the initial HPT grain orientations containing the basal planes perpendicular to the TD-RD plane.

A comprehensive analysis was conducted to determine the distributions of the misorientation angles in the EBSD maps in Figure 3 and the results are shown in Figure 4. It is important to note that all of these plots correspond to the grain-to-grain misorientation distributions ${ }^{[39,40]}$ rather than the pixel to pixel misorientations. The solid curves shown above the distributions in Figure 4 correspond to the distributions of the misorientation angles that were developed for an aggregate of randomly oriented hexagonal crystals using a Monte-Carlo method. ${ }^{[41-43]}$ This method was used also to develop the well-known Mackenzie random distributions for misorientations in fcc materials. ${ }^{[44,45]}$ It is observed that after long-term annealing in Figure 4(b) the distribution of the misorientation angles tends towards the normal Mackenzie distribution of misorientions for the non-basal plane of hcp materials whereas after short-term 
annealing the distributions are similar to the initial HPT-processed sample containing higher intensity peaks in the vicinities of $30^{\circ}$ and $90^{\circ}$.

In order to understand the textural evolution during the post-deformation annealing, the relevant pole figures of the EBSD orientation maps are shown in Figure 5 for the same four testing conditions. These results show that the basal planes are typically aligned parallel to ND and therefore parallel to the HPT loading direction. By applying a compressive pressure during the torsional straining, the $c$-axes of the majority of hcp crystals tend to rotate and align with the compressive direction so that the basal planes are parallel to the TD-RD plane of the HPT processing. Consequently, this produces a strong basal fiber texture of $\{0001\}\langle u v t w\rangle$. From the pole figures in Figure 5 it is also apparent that generally there is no change in the final position of the basal planes after long-term annealing for $2500 \mathrm{~min}$ at $450 \mathrm{~K}$ and a similar condition exists after short-term annealing at $473 \mathrm{~K}$. Nevertheless, it is apparent that the post-deformation annealing may decrease the maximum intensities of the basal planes.

\subsection{Hardness and mechanical testing before and after post-deformation annealing}

Figure 6 provides a detailed summary of the microhardness measurements with the individual datum points recorded close to the upper planes of the HPT disks along randomly selected diameters. In Figure 6(a) the initial unprocessed hardness is $\mathrm{Hv} \approx 75$ but after HPT for 5 turns the hardness is increased to $\mathrm{Hv} \approx 125$ and this value is reasonably constant across the disk except for slightly larger values at the outer edges. By annealing for $2500 \mathrm{~min}$ at $450 \mathrm{~K}$ it is apparent from Figure 6(a) that the microhardness drops to $\mathrm{Hv} \approx 85$ but again remains reasonably constant across the disk diameter. Figure 6(b) shows the effect of short-term annealing on the microhardness where all values for anneals of both 10 and 20 min lie within the range of $\mathrm{Hv} \approx 80$ 95. Close inspection of these data shows that, although all of the results are reasonably similar, 
annealing at higher temperatures tends to increase the restoration processes such as recovery and recrystallization $^{[46]}$ and this produces slightly larger grains as shown in Figure 2(d) and slightly lower hardness values. Since the grain size is related to the hardness value through the Hall-Petch relationship, the formation of larger recrystallized grains after annealing effectively decreases the microhardness values.

An objective of the post-deformation annealing was to evaluate the potential for achieving a combination of high strength and high ductility in tensile testing at RT. Tensile testing was therefore conducted both for the HPT-processed material and after short-term and long-term annealing. Specimens were tested at initial strain rates of $1.0 \times 10^{-4}$ and $1.0 \times 10^{-3} \mathrm{~s}^{-1}$ and the results for the faster strain rate are shown in Figure 7 plotted as engineering stress versus engineering strain. These curves provide a clear demonstration that post-deformation annealing at 20 min improves the ductility from an initial value of $\sim 15 \%$ to a value of $\sim 25 \%$ with little or no significant effect on the measured flow stresses.

All samples were pulled to failure and the fractography is illustrated in Figure 8 where the left column shows the sample in the HPT-processed condition and the right column illustrates a representative sample processed by HPT and then annealed for $20 \mathrm{~min}$ at $473 \mathrm{~K}$. It is apparent that the broken sample without annealing in Figure 8 is representative of brittle fracture with platelike features suggesting cleavage fracture along either twin boundaries or shear bands. By contrast, the post-HPT annealed sample shows failure inclined at an angle of $\sim 45^{\circ}$ to the tensile axis. The fracture surfaces are illustrated in the lower images as top views looking down onto the surfaces and as side views at two different magnifications. Microvoids are present in the annealed sample after pulling to failure as shown in the lower image on the right in Figure 8 but these microvoids are reasonably uniform in size and they tend to match the measured grain size in the microstructure 
as shown in Figure 2(c). This suggests that the microvoids correspond to grain pullouts and generally there is a ductile fracture.

\section{Discussion}

It was discussed in earlier studies ${ }^{[25-30]}$ that an excellent grain refinement may be achieved in the ZK60 alloy after HPT processing at RT and excellent superplasticity may be obtained at high temperatures. Despite the success in achieving a highly-refined microstructure in the HPTprocessed ZK60 with excellent strength up to $\sim 270 \mathrm{MPa}$, it is readily apparent from Figure 7 that ductilities were obtained with elongations to failure of $<15 \%$ for the tests conducted at RT and a strain rate of $1.0 \times 10^{-3} \mathrm{~s}^{-1}$. Alternatively, imposing a short term annealing after the HPT processing has a significant effect on the microstructure as shown in Figs 1 and 3. Annealing at 473 and 548 $\mathrm{K}$ for $20 \mathrm{~min}$ increases the grain size rapidly to a range of $\sim 2-6 \mu \mathrm{m}$. Therefore, short term annealing produces static recrystallization with a bimodality both in the misorientation angles and in the grain size distributions where there are some very fine grains and some coarser grains. By increasing the annealing temperature, the grain morphology changes from reasonably equiaxed with an average grain size in the range of $\sim 3-4 \mu \mathrm{m}$ to structures containing abnormal elongated grains with bimodalities in the grain size distributions. The results show that recrystallization occurs when conducting short-term annealing at temperatures of 473 and $548 \mathrm{~K}$ and the larger grain sizes after the different annealing condition produce a drop in the microhardness values.

An investigation $^{[47]}$ of the grain size and microhardness evolution of HPT-processed AZ31 alloy during annealing in the range of 373 to $673 \mathrm{~K}$ for $1800 \mathrm{~s}$ showed that the material underwent recovery up to $423 \mathrm{~K}$, recrystallization at $423 \mathrm{~K}$ and grain growth at higher temperatures whereas there was no evidence for a difference in the annealing behavior of samples processed at different numbers of turns of HPT. Also, it was reported that the material followed a linear trend of 
increasing hardness as a function of the inverse of the square-root of the grain size up to grain size of $1 \mu \mathrm{m} \cdot{ }^{[47]}$ Similar behavior was observed in the present investigation after annealing samples at different temperatures for $20 \mathrm{~min}$ and these data are in good agreement with the Hall-Petch relationship as shown in Figure 9.

The corresponding stress-strain curves in Figure 7 for the samples processed by HPT and then subjected to short post-HPT annealing provide a very clear demonstration of the advantage of imposing a short term annealing on ZK60. The short post-HPT annealing at temperatures ranging from 473 to $528 \mathrm{~K}$ for 10 and $20 \mathrm{~min}$ improves the ductility of the material to a reasonable level with elongations to failure of up to $\sim 40 \%$. Although similar elongations were achieved after short post-HPT annealing at $548 \mathrm{~K}$, the strength of the material dropped significantly at this higher temperature.

It is reasonable to anticipate generally an increase in ductility at the expense of a decrease in strength. Figure 10 summarizes the variation of the ultimate tensile strength (UTS) and elongation to failure of post-HPT annealed ZK60 by comparison with the initial material. The measured values of the UTS divided by the UTS for the HPT material are plotted against the elongation to failure normalized to the value for the HPT material, $\varepsilon_{\mathrm{fl}} / \varepsilon_{\mathrm{fl}}-\mathrm{HPT}$. Datum points are shown in Figure 10 for testing strain rates of (a) $1.0 \times 10^{-4} \mathrm{~s}^{-1}$ and (b) $1.0 \times 10^{-3} \mathrm{~s}^{-1}$. The horizontal and vertical broken lines correspond to the points where these normalized values are equal to 1.0. The definition of conventional behavior and the high strength-high ductility (HSHD) region in Figure 10 were defined earlier. ${ }^{[22]}$ It is readily apparent that the ductilities of the HPT-processed materials were improved by post-deformation annealing. Although a slight UTS drop was observed for most of these conditions, a datum point with an optimum annealing condition of 473 $\mathrm{K}$ for $20 \mathrm{~min}$ was detected within the HSHD region at a strain rate of $1.0 \times 10^{-4} \mathrm{~s}^{-1}$. 
A heat treatment study of the as-cast ZK60 alloy ${ }^{[48]}$ showed that an optimized condition of solutionizing and aging time and temperature can lead to a peak value for the volume fraction of precipitates. This high density of the second phase precipitates with modified morphologies is beneficial to both the strength and ductility. Since the analysis in the current study showed that short post-HPT annealing has few effects on the textures and misorientation angle distributions of the HPT-processed materials, the simultaneous increase in strength and ductility while the grain size increased may be attributed directly to microstructural modifications by changes in the distributions and morphologies of precipitates.

Recent TEM observations on two-phase alloys processed by SPD show that SPD may lead to fragmentation and dissolution of precipitates within the matrix. ${ }^{[49,50]}$ In practice, the imposition of a high hydrostatic stress in SPD has a major effect on the nature of the precipitate morphology and the high strains during SPD may also lead to the decomposition of supersaturated solid solutions. ${ }^{[50]}$ Observations on the microstructure of a UFG Mg-3.4\% Zn alloy processed by $\mathrm{HPT}^{[51]}$ showed that there are two types of precipitates arising either from the dynamic precipitation during HPT or from the ageing treatment. A TEM study of precipitates in samples before and after heat treatment revealed the occurrence of dynamic precipitation during deformation with these precipitates mainly concentrated on the grain or sub-grain boundaries. Short term annealing at 423 $\mathrm{K}$ for $600 \mathrm{~s}$ led to the continuous growth of precipitates and further annealing up to $128 \mathrm{~h}$ shifted the precipitate sizes to higher values in the range of tens of nanometers. ${ }^{[51]}$ Therefore, in the present study on ZK60 a short term post-HPT annealing at $473 \mathrm{~K}$ for $20 \mathrm{~min}$ provided essentially the optimum condition for the size and dispersion of the precipitates in order to effectively enhance both the strength and the ductility of the HPT-processed material. 


\section{Conclusions}

1. The effect of post-HPT annealing was studied on a ZK60 magnesium alloy processed by 5 turns of HPT at RT under a pressure of $2.0 \mathrm{GPa}$. The microstructural and textural evolution were evaluated by orientation imaging microscopy and the mechanical behavior was investigated by microhardness measurements and miniature tensile experiments.

2. Short-term annealing spreads the span of the grain size distributions from the range of submicrometers to the range of micrometers but the post-HPT annealing has no effect on the misorientation angle distributions or the overall texture of the HPT-processed material.

3. Microhardness measurements show reasonable uniformity across the disks with a drop in all conditions up to $30 \%$ after annealing but these lower values are higher than in the as-received material. The elongations to failure were improved from $\sim 15 \%$ for the HPT-processed material to a maximum value of $\sim 40 \%$.

4. An optimum condition of annealing at $473 \mathrm{~K}$ for $20 \mathrm{~min}$ provided a high strength and reasonably high ductility in the HPT-processed ZK60 alloy. 


\section{References}

[1] F.H. Froes, D. Eliezer, E. Aghion, JOM 1998, 50, 30.

[2] K. Johnson, Adv. Mater. Proc. 2002, 160(6), 62.

[3] M.P. Staiger, A.M. Pietak, J. Huadmai, G. Dias, Biomaterials 2006, 27, 1728.

[4] K. Kubota, M. Mabuchi, K. Higashi, J. Mater. Sci. 1999, 34, 2255.

[5] T.G. Langdon, J. Mater. Sci. 2009, 44, 5998.

[6] A. Zhilyaev, T. Langdon, Prog. Mater. Sci. 2008, 53, 893.

[7] R.B. Figueiredo, S. Sabbaghianrad, A. Giwa, J.R. Greer, T.G. Langdon, Acta Mater. 2017, $122,322$.

[8] R.B. Figueiredo, F.S.J. Poggiali, C.L.P. Silva, P.R. Cetlin, T.G. Langdon, J. Mater. Sci. 2016, $51,3013$.

[9] R.B. Figueiredo, T.G. Langdon, Adv. Eng. Mater. 2008, 10, 37.

[10] R. Valiev, Nature 2002, 419, 887.

[11] R. Valiev, Nat. Mater. 2004, 3, 511.

[12] O. Andreau, J. Gubicza, N. Xian Zhang, Y. Huang, P. Jenei, T.G. Langdon, Mater. Sci. Eng. A 2014, 615, 231.

[13] N. Maury, N.X. Zhang, Y. Huang, A.P. Zhilyaev, T.G. Langdon, Mater. Sci. Eng. A 2015, 638, 174.

[14] T. Suo, Y.L. Li, F. Zhao, Q. Deng, K. Xie, Mater. Res. Innov. 2011, 15, s69.

[15] I. Semenova, G. Salimgareeva, G. Da Costa, W. Lefebvre, R. Valiev, Adv. Eng. Mater. 2010, 12, 803.

[16] A. V. Polyakov, I.P. Semenova, R.Z. Valiev, Y. Huang, T.G. Langdon, MRS Commun. 2013, 3, 249.

[17] A. V. Polyakov, I.P. Semenova, Y. Huang, R.Z. Valiev, T.G. Langdon, Adv. Eng. Mater. 2014, 16, 1038.

[18] I.P. Semenova, A. V. Polyakov, V. V. Polyakova, Y. Huang, R.Z. Valiev, T.G. Langdon, Adv. Eng. Mater. 2016, 18, 2057.

[19] E.O. Hall, Proc. Phys. Soc. Sect. B 1951, 64, 747. 
[20] 20. N.J. Petch, J. Iron Steel Inst 1953, 174, 25.

[21] R.Z. Valiev, I. V Alexandrov, Y.T. Zhu, T.C. Lowe, J. Mater. Res. 2002, 17, 5.

[22] T. Mungole, P. Kumar, M. Kawasaki, T.G. Langdon, J. Mater. Res. 2014, 29, 2534.

[23] P. Kumar, M. Kawasaki, T.G. Langdon, J. Mater. Sci. 2016, 51, 7.

[24] R. Valiev, Scr. Mater. 2003, 49, 669.

[25] S.A. Torbati-Sarraf, S. Sabbaghianrad, T.G. Langdon, Lett. Mater. 2015, 5, 287.

[26] S.A. Torbati-Sarraf, T.G. Langdon, Adv. Mater. Res. 2014, 922, 767.

[27] S.A. Torbati-Sarraf, T.G. Langdon, J. Alloys Compd. 2014, 613, 357.

[28] H.-J. Lee, B. Ahn, M. Kawasaki, T.G. Langdon, J. Mater. Res. Technol. 2015, 4, 18.

[29] I.-C. Choi, D.-H. Lee, B. Ahn, K. Durst, M. Kawasaki, T.G. Langdon, J. Jang, Scr. Mater. 2015, 94, 44.

[30] S.A. Torbati-Sarraf, S. Sabbaghianrad, R.B. Figueiredo, T.G. Langdon, J. Alloys Compd. 2017, 712, 185.

[31] R.B. Figueiredo, P.R. Cetlin, T.G. Langdon, Mater. Sci. Eng. A 2011, 528, 8198.

[32] R.B. Figueiredo, P.H.R. Pereira, M.T.P. Aguilar, P.R. Cetlin, T.G. Langdon, Acta Mater. 2012, 60, 3190 .

[33] K. Edalati, Z. Horita, T.G. Langdon, Scr. Mater. 2009, 60, 9.

[34] A. Loucif, R.B. Figueiredo, M. Kawasaki, T. Baudin, F. Brisset, R. Chemam, T.G.

Langdon, J. Mater. Sci. 2012, 47, 7815.

[35] Y. Huang, R.B. Figueiredo, T. Baudin, F. Brisset, T.G. Langdon, Adv. Eng. Mater. 2012, $14,1018$.

[36] Y. Huang, R.B. Figueiredo, T. Baudin, A.-L. Helbert, F. Brisset, T.G. Langdon, Mater. Res. 2013, 16, 577.

[37] R.B. Figueiredo, T.G. Langdon, J. Mater. Sci. 2009, 44, 4758.

[38] R.B. Figueiredo, T.G. Langdon, Int. J. Mater. Res. 2009, 100, 1638.

[39] L.S. Tóth, B. Beausir, C.F. Gu, Y. Estrin, N. Scheerbaum, C.H.J. Davies, Acta Mater. 2010, $58,6706$.

[40] L.S. Toth, C. Gu, Mater. Charact. 2014, 92, 1. 
[41] J.A. Del Valle, M.T. Pérez-Prado, O.A. Ruano, Rev. Metal. 2002, 38, 353.

[42] J.A. del Valle, M.T. Pérez-Prado, O.A. Ruano, Metall. Mater. Trans. A 2005, 36, 1427.

[43] J. Delvalle, O. Ruano, Acta Mater. 2007, 55, 455.

[44] J.K. Mackenzie, Biometrika 1958, 45, 229.

[45] J.K. Mackenzie, M.J. Thomson, Biometrika 1957, 44, 205.

[46] S.E. Ion, F.J. Humphreys, S.H. White, Acta Metall. 1982, 30, 1909.

[47] L.R.C. Malheiros, R.B. Figueiredo, T.G. Langdon, J. Mater. Res. Technol. 2015, 4, 14.

[48] C. Xian-hua, H. Xiao-wang, P. Fu-sheng, T. Ai-tao, W. Jing-feng, Z. Ding-fei, Trans. Nonferrous Met. Soc. China 2011, 21, 754.

[49] B. Li, S. Joshi, K. Azevedo, E. Ma, K.T. Ramesh, R.B. Figueiredo, T.G. Langdon, Mater. Sci. Eng. A 2009, 517, 24.

[50] B.B. Straumal, V. Pontikis, A.R. Kilmametov, A.A. Mazilkin, S.V. Dobatkin, B. Baretzky, Acta Mater. 2017, 122, 60.

[51] F. Meng, J.M. Rosalie, A. Singh, K. Tsuchiya, Mater. Sci. Eng. A 2015, 644, 386. 


\section{Figure captions:}

Fig. 1. IQ maps of ZK60 magnesium alloy processed by (a) 5 turns of HPT, and 5 turns of HPT followed by post-HPT annealing for (b) long term after $2500 \mathrm{~min}$ at $450 \mathrm{~K}$, and short term annealing for $20 \mathrm{~min}$ at temperatures of (c) $473 \mathrm{~K}$ and (d) $548 \mathrm{~K}$.

Fig. 2. Grain size distribution of ZK60 magnesium alloy processed by (a) 5 turns of HPT, and 5 turns of HPT followed by post-HPT annealing for (b) long term after $2500 \mathrm{~min}$ at $450 \mathrm{~K}$, and short term annealing for 20 min at temperatures of (c) $473 \mathrm{~K}$ and (d) $548 \mathrm{~K}$.

Fig. 3. EBSD maps of ZK60 magnesium alloy processed by (a) 5 turns of HPT, and 5 turns of HPT followed by post-HPT annealing for (b) long term after $2500 \mathrm{~min}$ at $450 \mathrm{~K}$, and short term annealing for $20 \mathrm{~min}$ annealing at temperatures of (c) $473 \mathrm{~K}$ and (d) $548 \mathrm{~K}$.

Fig. 4. Number fraction of the misorientation angles of ZK60 magnesium alloy processed by (a) 5 turns of HPT, and 5 turns of HPT followed by post-HPT annealing for (b) long term after 2500 min at $450 \mathrm{~K}$, and short term annealing for 20 min annealing at temperatures of (c) $473 \mathrm{~K}$ and (d) $548 \mathrm{~K}$.

Fig. 5. The pole figure of $\{0001\},\{101 \overline{0}\}$ and $\{21 \overline{1} \overline{0}\}$ crystallographic orientations on the TDRD plane and normal to the ND of HPT direction from the mid-radius of samples processed by 5 turns of HPT and after post-HPT annealing.

Fig. 6. Vickers microhardness across diameters of disks of the ZK60 processed through 5 turns of HPT and annealed for (a) long term and (b) short term at different temperatures: the lower dashed line shows the as-received condition.

Fig. 7. Typical Engineering stress vs engineering strain curves of samples annealed for $20 \mathrm{~min}$ after HPT and tested at a strain rate of $1.0 \times 10^{-3} \mathrm{~s}^{-1}$. 
Fig. 8. The SEM fractography of tensile specimens tested at room temperature for material processed by 5 turns of HPT and after post-HPT annealing at $473 \mathrm{~K}$ for $20 \mathrm{~min}$.

Fig. 9. Hall-Petch relationship of ZK60 processed by HPT and subsequently annealed for $20 \mathrm{~min}$.

Fig. 10. Variation of the normalized UTS with the normalized elongation to failure of samples after post-HPT annealing and pulling to failure at RT at strain rates of (a) $1.0 \times 10^{-4} \mathrm{~s}^{-1}$ and (b) 1.0 $\times 10^{-3} \mathrm{~s}^{-1}$. 


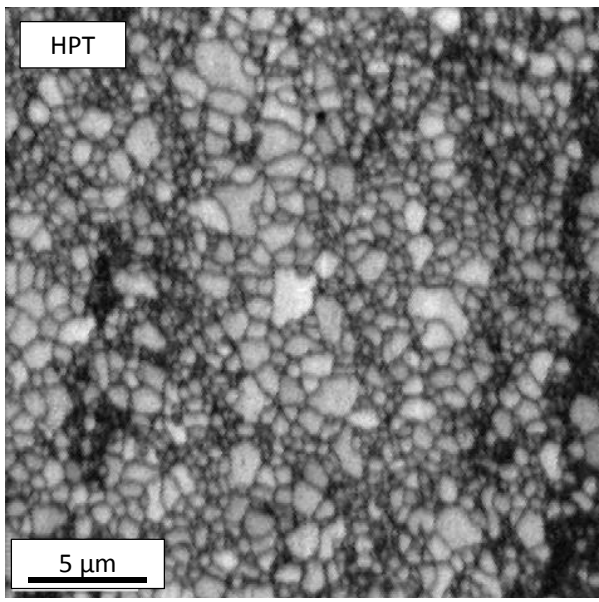

(a)

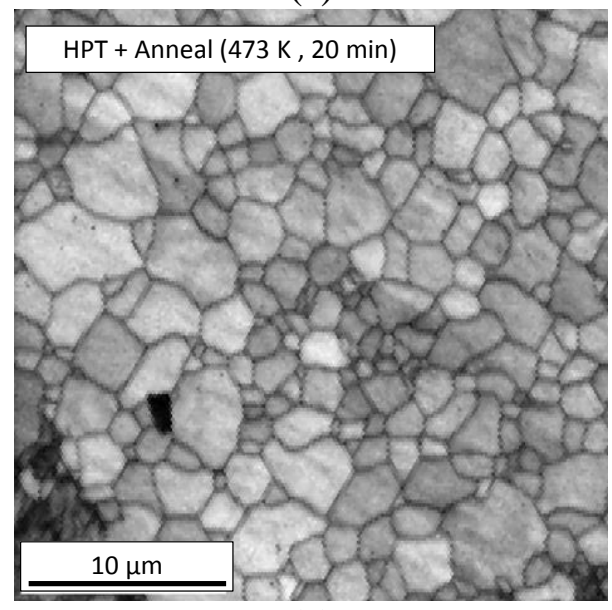

(c)

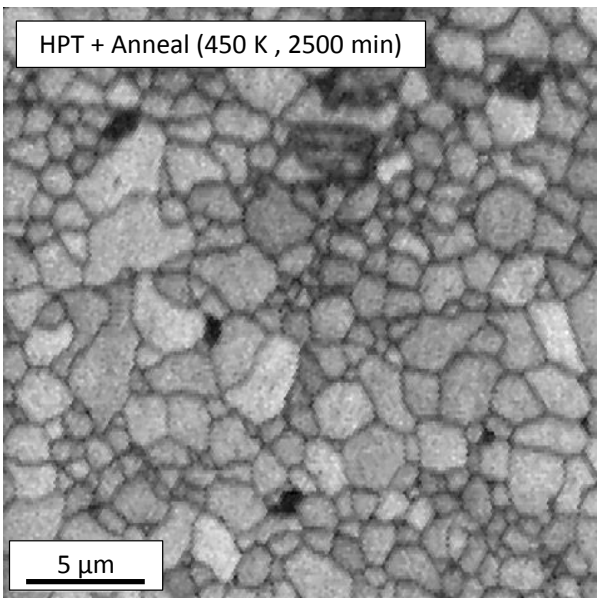

(b)

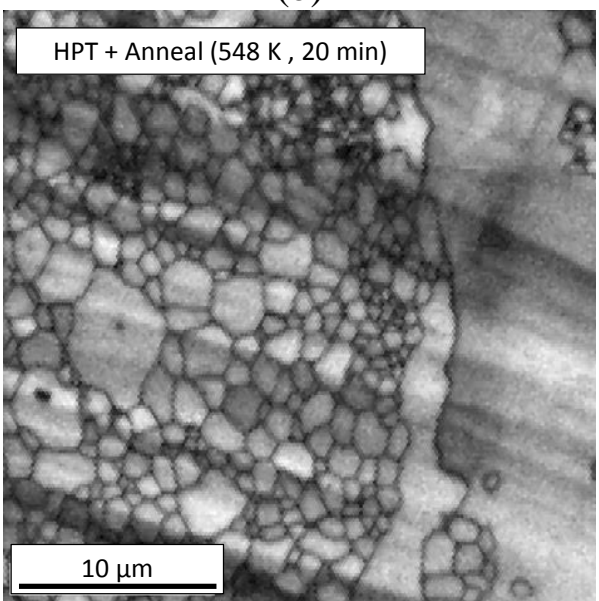

(d)

Figure 1. IQ maps of ZK60 magnesium alloy processed by (a) 5 turns of HPT, and 5 turns of HPT followed by post-HPT annealing for (b) long term after $2500 \mathrm{~min}$ at $450 \mathrm{~K}$, and short term annealing for $20 \mathrm{~min}$ at temperatures of (c) $473 \mathrm{~K}$ and (d) $548 \mathrm{~K}$. 


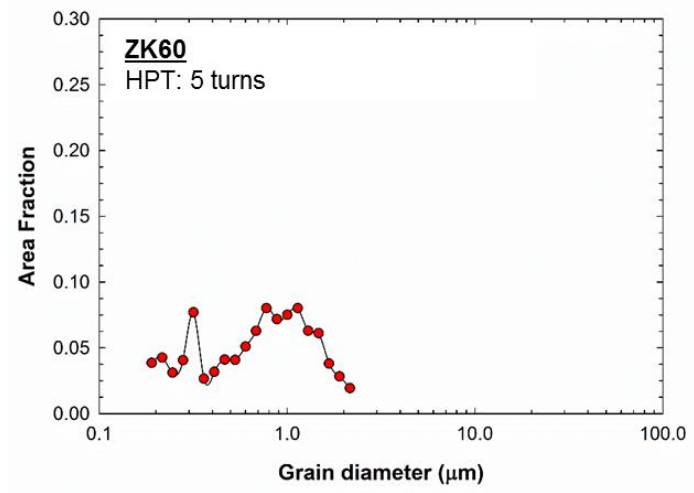

(a)

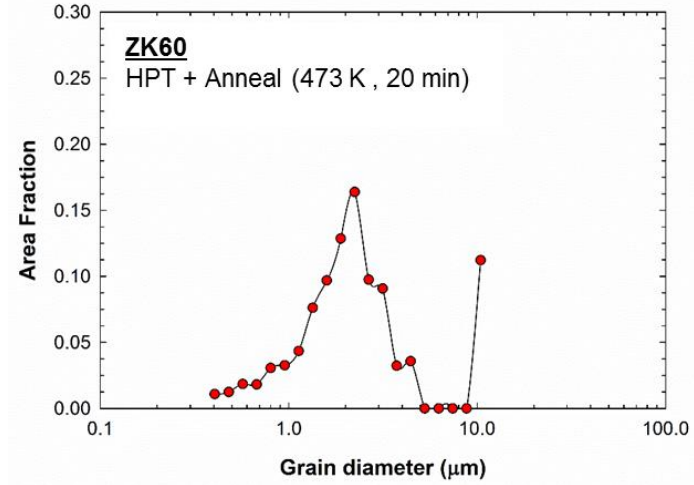

(c)

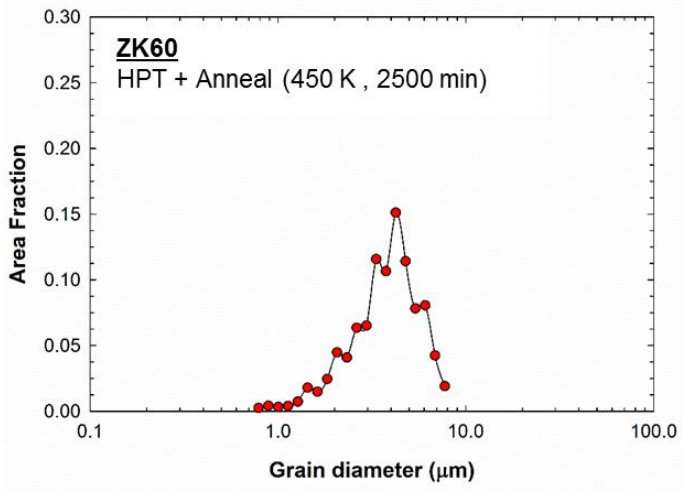

(b)

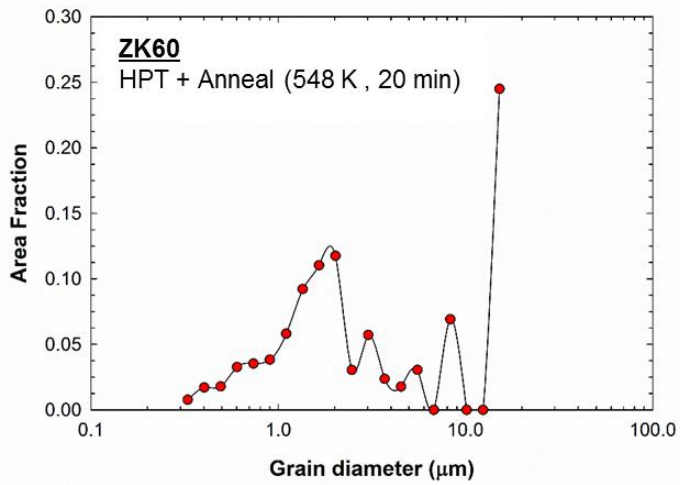

(d)

Figure 2. Grain size distribution of ZK60 magnesium alloy processed by (a) 5 turns of HPT, and 5 turns of HPT followed by post-HPT annealing for (b) long term after 2500 min at $450 \mathrm{~K}$, and short term annealing for $20 \mathrm{~min}$ at temperatures of (c) $473 \mathrm{~K}$ and (d) $548 \mathrm{~K}$. 


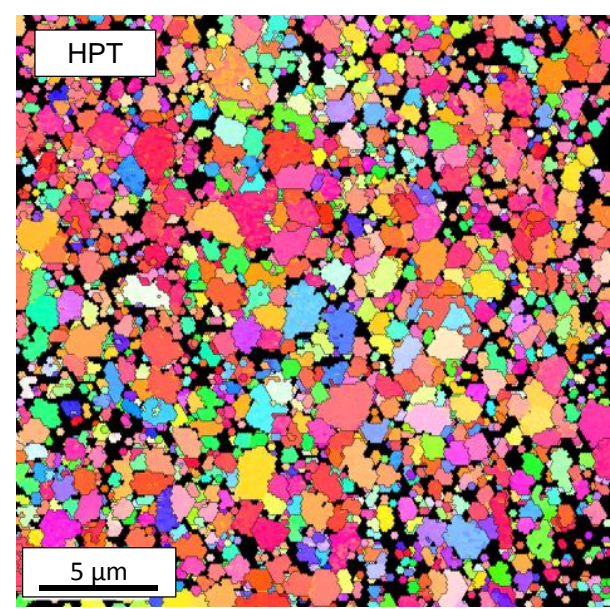

(a)

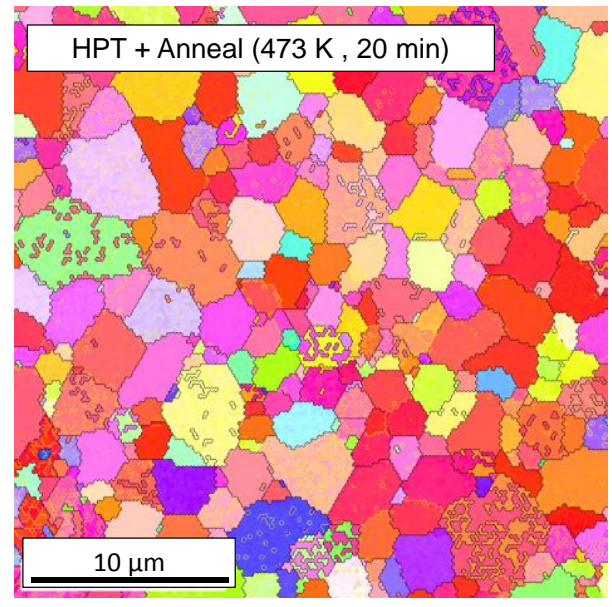

(c)

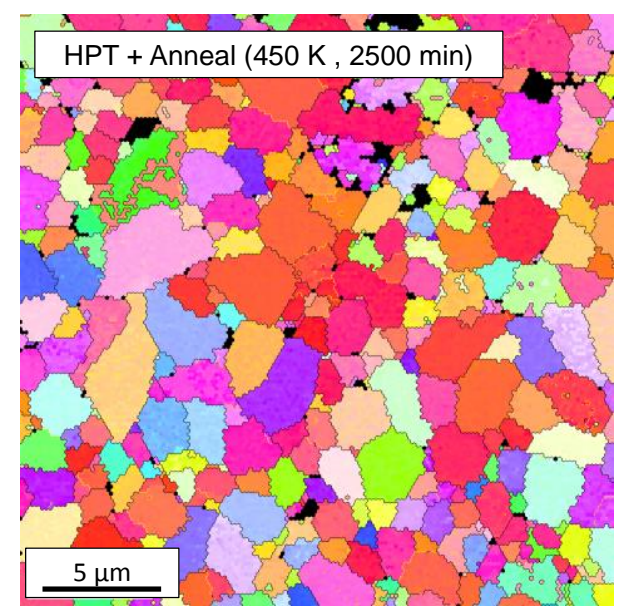

(b)

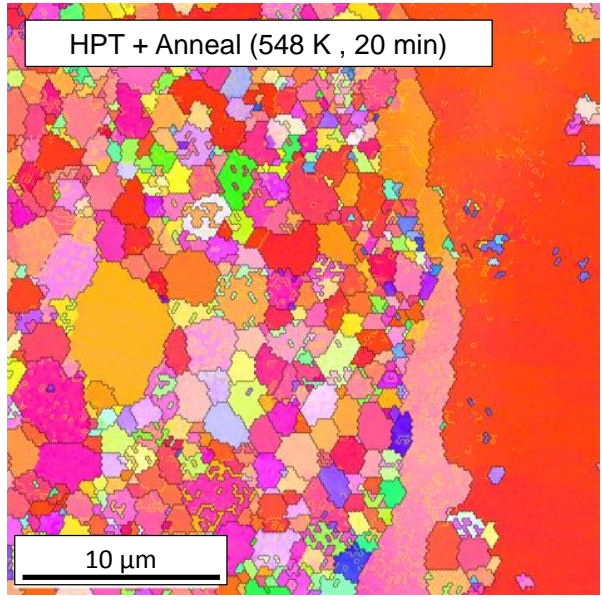

(d)

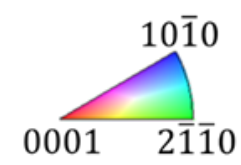

Figure 3. EBSD maps of ZK60 magnesium alloy processed by (a) 5 turns of HPT, and 5 turns of HPT followed by post-HPT annealing for (b) long term after $2500 \mathrm{~min}$ at $450 \mathrm{~K}$, and short term annealing for $20 \mathrm{~min}$ annealing at temperatures of (c) $473 \mathrm{~K}$ and (d) $548 \mathrm{~K}$. 


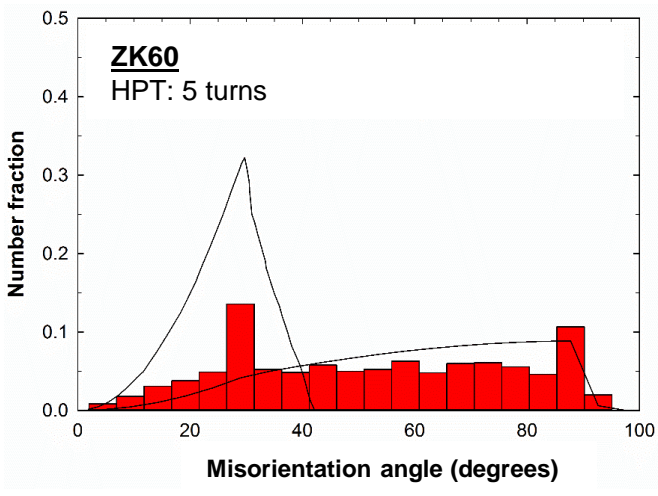

(a)

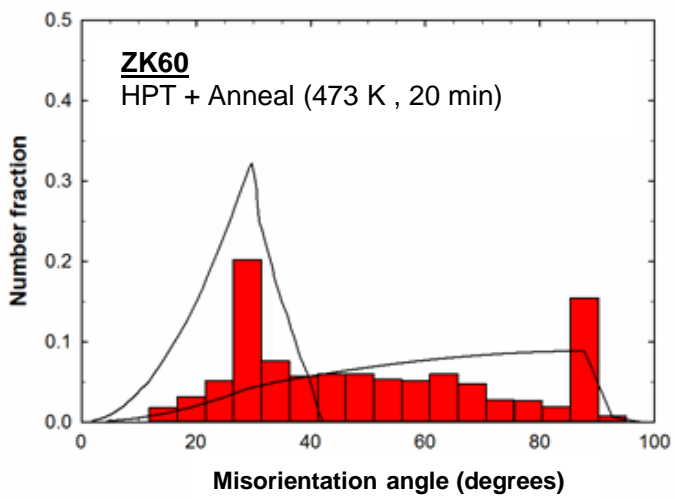

(c)

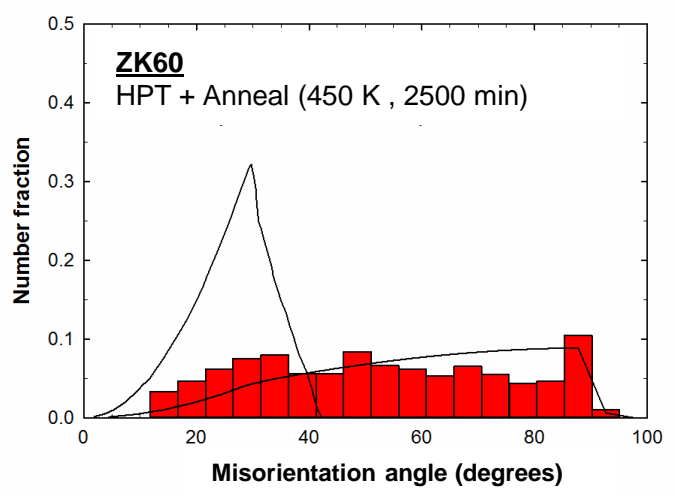

(b)

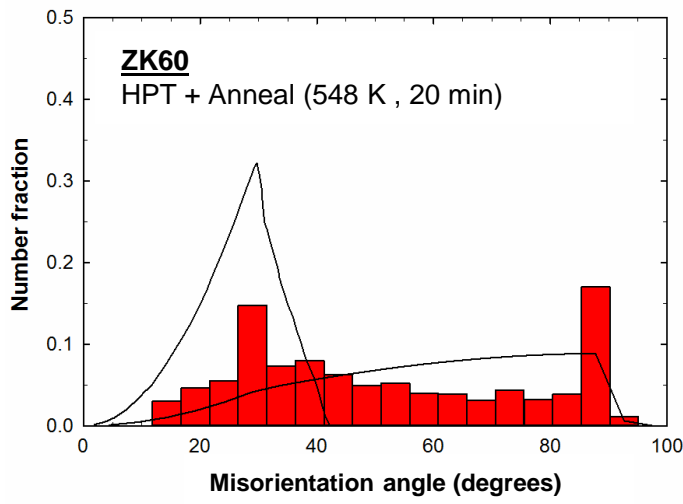

(d)

Figure 4. Number fraction of the misorientation angles of ZK60 magnesium alloy processed by (a) 5 turns of HPT, and 5 turns of HPT followed by post-HPT annealing for (b) long term after $2500 \mathrm{~min}$ at $450 \mathrm{~K}$, and short term annealing for $20 \mathrm{~min}$ annealing at temperatures of (c) $473 \mathrm{~K}$ and (d) $548 \mathrm{~K}$. 


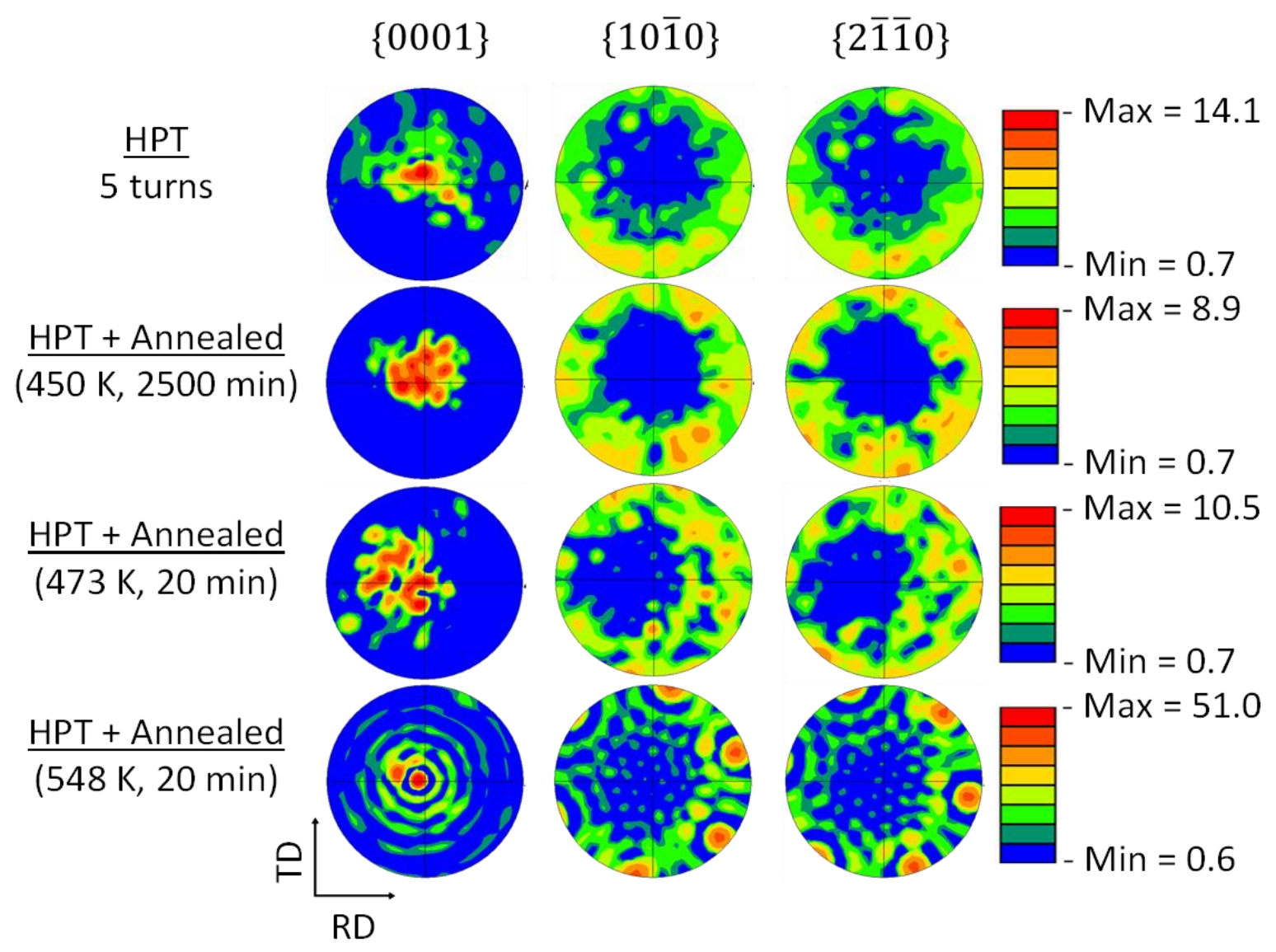

Figure 5. The pole figure of $\{0001\},\{10 \overline{1} 0\}$ and $\{2 \overline{1} \overline{1} 0\}$ crystallographic orientations on the TD-RD plane and normal to the ND of HPT direction from the mid-radius of samples processed by 5 turns of HPT and after post-HPT annealing. 


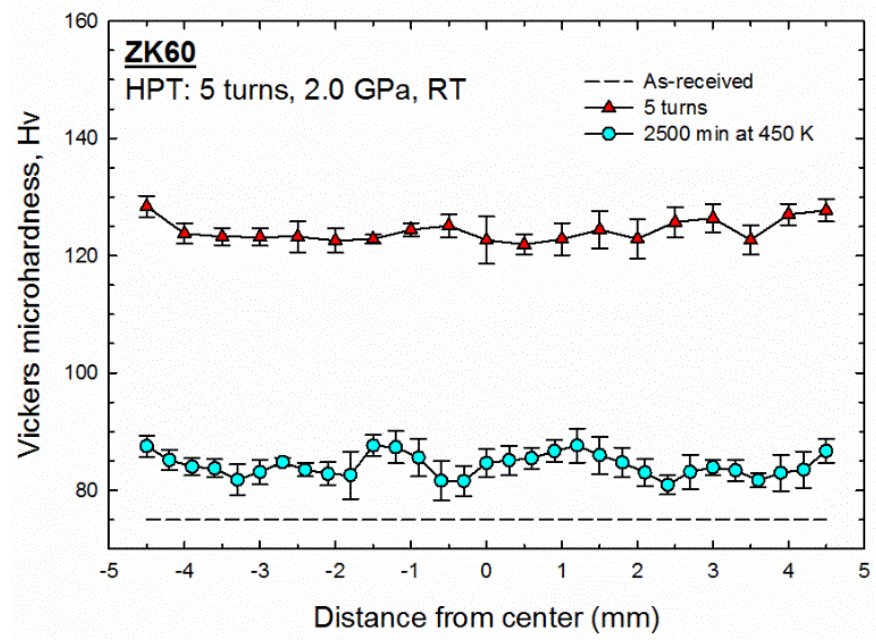

(a)

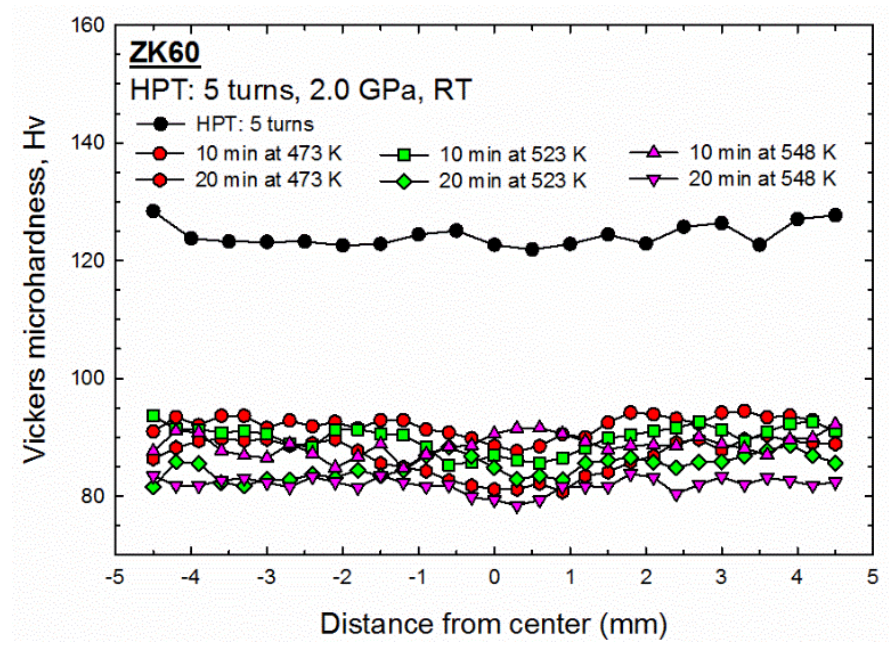

(b)

Figure 6. Vickers microhardness across diameters of disks of the ZK60 processed through 5 turns of HPT and annealed for (a) long term and (b) short term at different temperatures: the lower dashed line shows the as-received condition. 


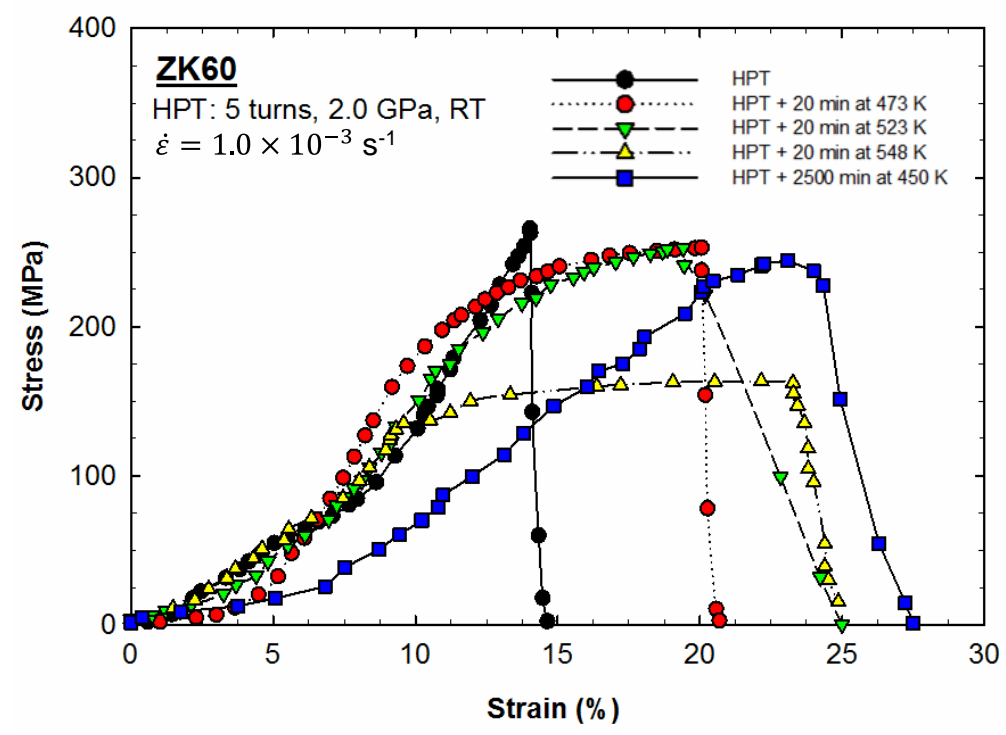

Figure 7. Typical Engineering stress vs engineering strain curves of samples annealed for $20 \mathrm{~min}$ after HPT and tested at a strain rate of $1.0 \times 10^{-3} \mathrm{~s}^{-1}$. 


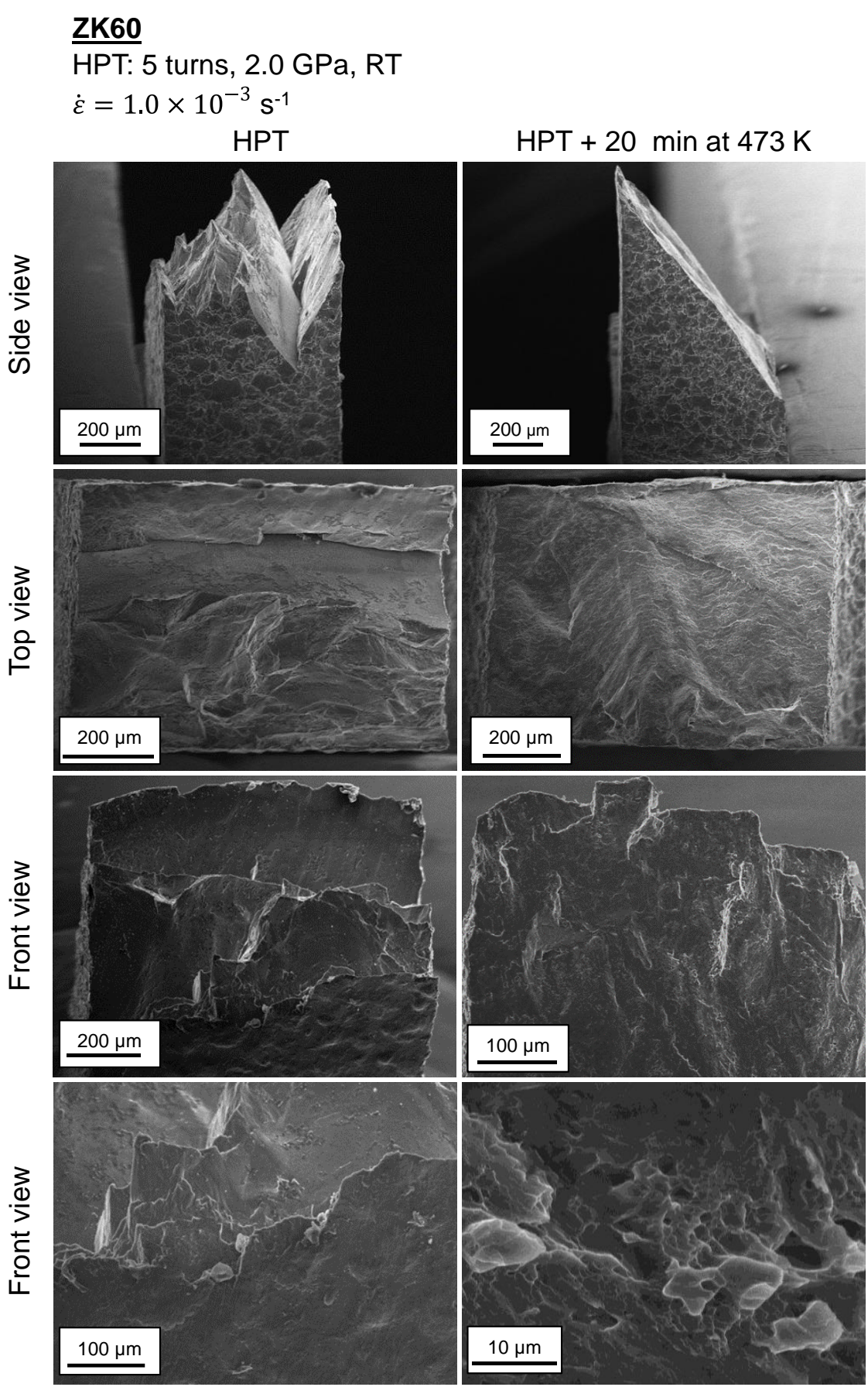

Figure 8. The SEM fractography of tensile specimens tested at room temperature for material processed by 5 turns of HPT and after post-HPT annealing at $473 \mathrm{~K}$ for $20 \mathrm{~min}$. 


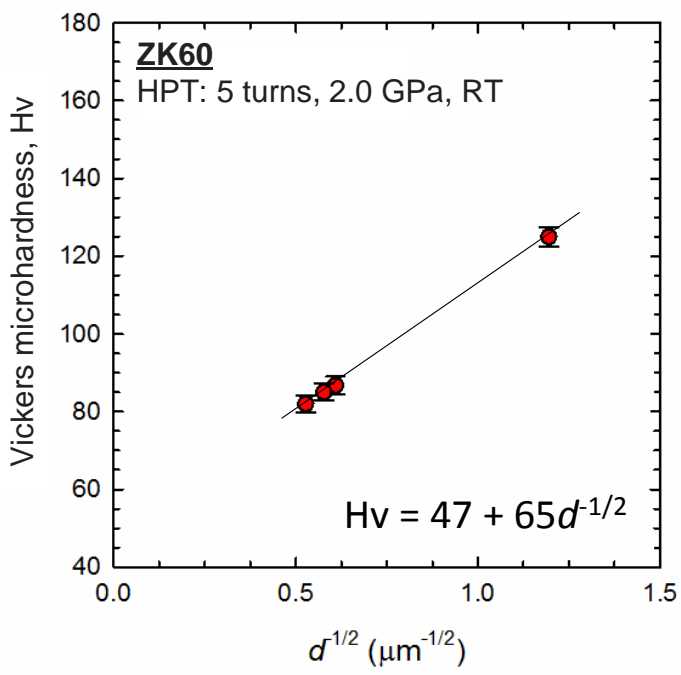

Figure 9. Hall-Petch relationship of ZK60 processed by HPT and subsequently annealed for $20 \mathrm{~min}$. 


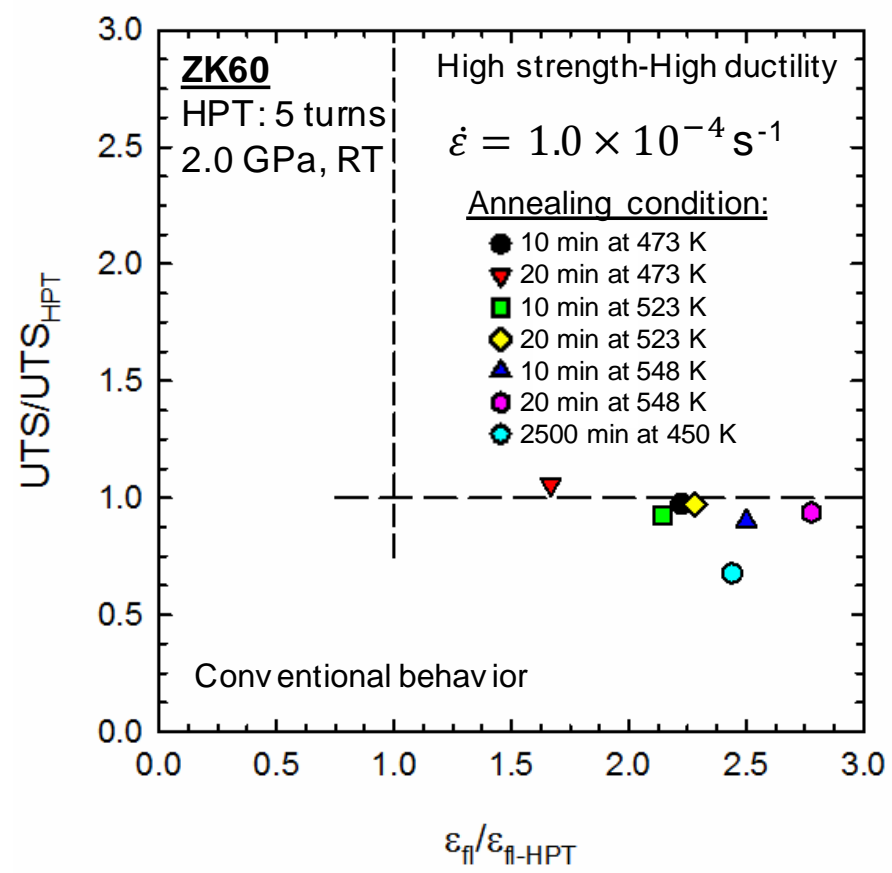

(a)

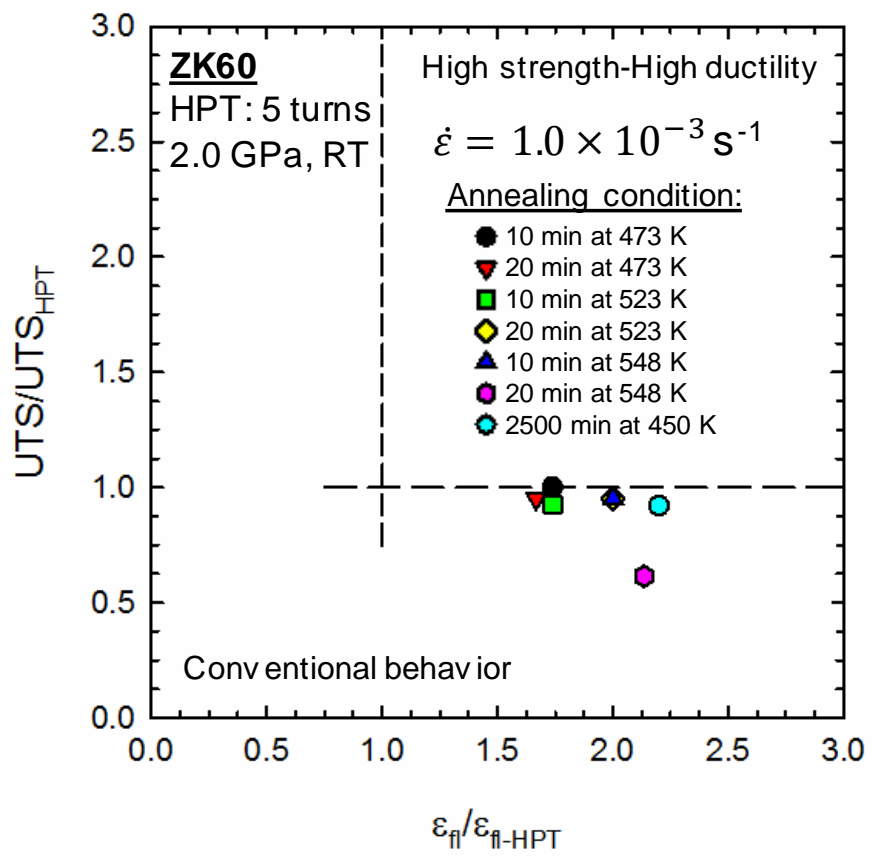

(b)

Figure 10. Variation of the normalized UTS with the normalized elongation to failure of samples after post-HPT annealing and pulling to failure at RT at strain rates of (a) $1.0 \times 10^{-4} \mathrm{~s}^{-1}$ and (b) $1.0 \times 10^{-3} \mathrm{~s}^{-1}$. 